Pure Appl. Chem., Vol. 72, No. 12, pp. 2259-2264, 2000.

(C) 2000 IUPAC

\title{
Mechanisms and consequences of oxygen transfer reactions*
}

\author{
Peter Beak ${ }^{\dagger}$, David R. Anderson, Stephen G. Jarboe, \\ Mitchell L. Kurtzweil, and Keith W. Woods \\ Department of Chemistry, University of Illinois at Urbana-Champaign, Urbana, IL \\ 61801, USA
}

\begin{abstract}
The geometry about oxygen in the transition-state structures for oxygen transfers from a nitrone to phosphorous, from a percarboxylic acid to a carbon-carbon double bond, and from an $\mathrm{N}$-sulfonyl oxaziridine to a carbon-carbon double bond have been evaluated by the endocyclic restriction test. The former can proceed at an oblique angle, while the latter two require a large angle between the entering and leaving groups on oxygen. This information is used to determine the mechanism of the aldehyde-dependent oxygen transfer from molecular oxygen to a carbon-carbon double bond.
\end{abstract}

Many chemical reactions, when broken down to their elementary steps, are atom transfer processes. Proper descriptions of the pathways of these reactions require experimental determinations of the arrangement of atoms in transition-state structures. With this information in hand, an informed choice between alternative pathways may be made, and understanding of the mechanism can be developed.

The endocyclic restriction test is based on work by Eschenmoser, who investigated nucleophilic substitution of carbon and Hogg and Vipond who investigated nucleophilic displacements at sulfur [1-3]. We have used this approach to evaluate the orientation of atoms in transition-state structures for reactions in which the atom $Y$ is transferred from the leaving group $L$ to a nucleophile $N$. The test determines whether the transfer of $\mathrm{Y}$ from $\mathrm{L}$ to $\mathrm{N}$ can occur in an endocyclic ring. The size of the ring restricts the bond angles available in a transition-state structure (2) [1]. Experimentally, the approach involves determination of whether reaction (2) is intramolecular or intermolecular.

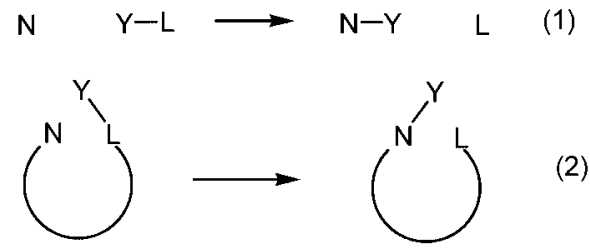

For example, if a nucleophile and leaving group are linked by three methylene groups, the atom transfer could occur intramolecularly or intermolecularly (3). An intramolecular reaction would be observed if N-Y-L bond angle of approximately $120^{\circ}$ would be accessible in a transition-state structure. If that or a smaller bond angle were not possible for the transfer of atom $\mathrm{Y}$, the reaction could proceed in an intermolecular mode. In order to obtain a sound mechanistic conclusion, evaluation of a dissociative reaction would be required.

*Plenary lecture presented at the $15^{\text {th }}$ International Conference on Physical Organic Chemistry (ICPOC 15), Göteborg, Sweden, 8-13 July 2000. Other presentations are published in this issue, pp. 2219-2358.

$\dagger$ Corresponding author 


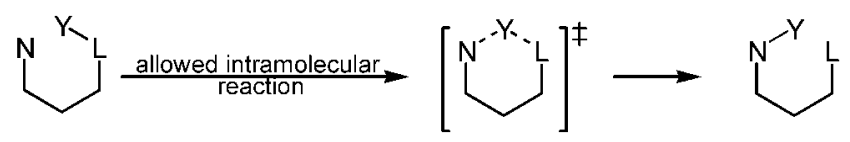

Experimental determination of the molecularity of the reaction can be achieved by an isotopic double labeling or by kinetic experiments. If these approaches are inadequate, alternatives, including competitive intramolecular transfers or the use of surrogate intermolecular reporter molecules may be employed. A notable feature of the endocyclic restriction test is its applicability to nonstereogenic atoms and its ability to afford definitive information, even for low-yielding reactions. The present report summarizes our investigations of the geometries of oxygen transfer reactions and shows how the information obtained from these studies allows the determination of a reaction mechanism of oxygen transfer in a case that was ambiguous.

\section{OXYGEN TRANSFER FROM A NITRONE TO A PHOSPHINE}

The transfer of oxygen from a nitrone to phosphorous has been investigated for the conversion of a nitrone phoshine to an imine phosphine oxide (4). This reaction was shown, by double labeling, to be intramolecular in a six-membered endocyclic ring. A pathway that allows a small bond angle between the entering and leaving groups on oxygen is available for the reaction. Substituent effects are most consistent with a six-membered ring transition structure with valance expansion at phosphorous (4) [4].<smiles>CC(C)(C)N=Cc1ccccc1P(=O)(O)c1ccccc1</smiles><smiles>C[13C](C)[N+]1=Cc2ccccc2[PH](c2ccccc2)(c2ccccc2)O1</smiles>

\section{OXYGEN TRANSFER FROM A PERCARBOXYLIC ACID TO A DOUBLE BOND}

We have established by double-labeling experiments that the transfer of oxygen from a peroxycarboxylic acid to an olefin to provide an epoxide is an intermolecular reaction in an 8-membered endocyclic ring, but is intramolecular in a 16-membered endocyclic ring (5) [5]. This result is consistent with the transition structure proposed many years ago by P. D. Bartlett which has come to be known as the "butterfly mechanism" [6]. This experiment shows that a large bond angle between the double bond and the oxygen-oxygen bond is required in the transition-state structure (5).

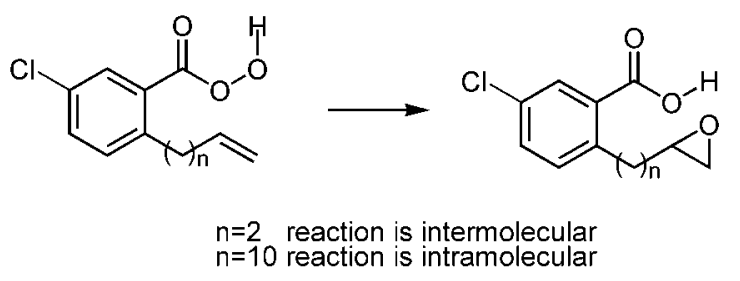

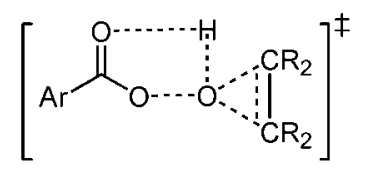

(C) 2000 IUPAC, Pure and Applied Chemistry 72, 2259-2264 


\section{OXYGEN TRANSFER FROM AN OXAZIRIDINE TO A DOUBLE BOND}

Epoxidation of olefins by $\mathrm{N}$-sulfonyl oxaziridines, developed by Davis, has become a widely used reaction [7]. Transition-state structures in which oxygen transfer occurs with simultaneous $\mathrm{N}-\mathrm{O}$ and $\mathrm{C}-\mathrm{O}$ bond breaking or with $\mathrm{N}-\mathrm{O}$ bonds significantly leading $\mathrm{C}-\mathrm{O}$ bond cleavage have been suggested. In order to distinguish these possibilities, two systems which restrain the possible transition-state structures have been investigated [8]. A double-labeling experiment carried out with a prospective five-membered ring established the reaction to be an intramolecular process (6). The disposition of the double bond and the nitrogen-oxygen bond rules out predominant $\mathrm{C}-\mathrm{O}$ cleavage and allows transition-state structure with either simultaneous $\mathrm{N}-\mathrm{O}, \mathrm{C}-\mathrm{O}$, or predominant $\mathrm{N}-\mathrm{O}$ bond cleavage. An investigation of linear free-energy effects in this constrained system provided a $\rho$ value consistent with that previously reported for intermolecular reactions, establishing that this endocyclic oxygen transfer exhibits the same electronic characteristics as an unconstrained process.<smiles>CC(C)=Cc1ccccc1C1ON1S(=O)(=O)c1ccccc1</smiles>

In order to more fully evaluate the reaction trajectory, an investigation of a differently structured system was carried out (7). Because analytical difficulties precluded the use of double labeling to evaluate the molecularity of the reaction, the conversion was carried out in the presence of an intermolecular reporter (7). If the reaction were intermolecular, the expected products would be the epoxide sulfonimine and the epoxide sulfonamide. If the reaction was intramolecular, only the former product would be observed. In the experiment, both epoxides were observed, consistent with an intermolecular oxygen transfer. This result may be attributed to a large angle required for the double bond to approach the nitrogen-oxygen bond. Hence, the geometric constraint of a trigonal bipyramid that was observed for oxygen-oxygen bond cleavage of the percarboxylic acid oxygen applies to the nitrogen-oxygen bond cleavage of an oxaziridine.

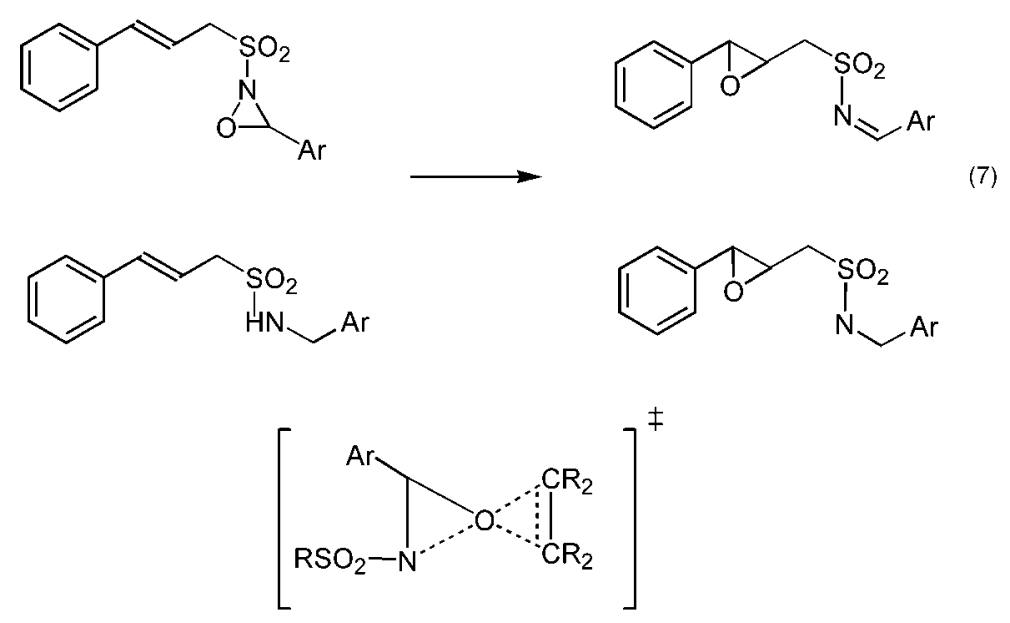

\section{OXYGEN TRANSFER FROM MOLECULAR OXYGEN IN THE PRESENCE OF AN ALDEHYDE TO A DOUBLE BOND}

The knowledge of the transition structures that has been provided by previous studies offers a basis for determination of the mechanism of olefin epoxidation by oxygen in the presence of an aldehyde [9]. It 
had been reported that this reaction was stereospecific and uncatalyzed but also that such an epoxidation could be metal ion catalyzed and nonstereospecific (8).

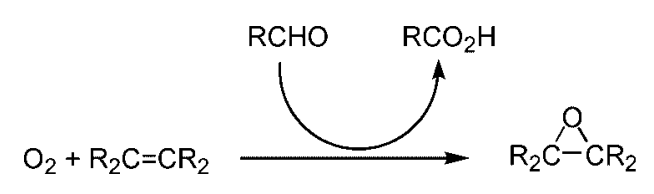

In our experience, the reaction did not proceed in the absence of aldehyde and required a peroxide initiator. The most reasonable oxidizing agents for the sequence are a percarboxylic radical formed from the acyl radical from the aldehyde or a percarboxylic acid formed from the percarboxylic radical (9).

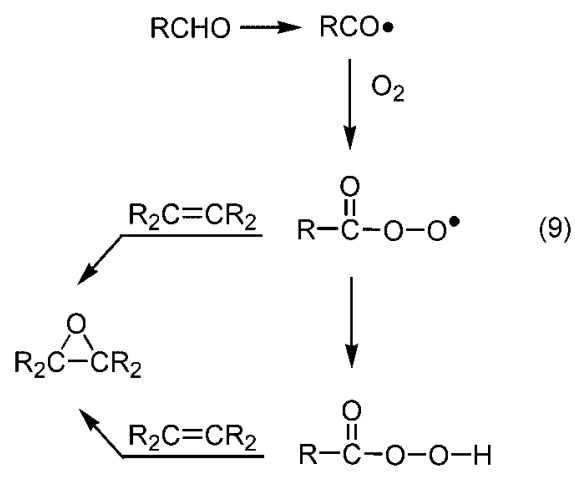

The geometrical requirement established for oxygen transfer from a percarboxylic acid to an olefin (vide supra) was used to design an endocyclic restriction test to distinguish the possibilities (10). From the olefinic aldehyde reactant formation of a percarboxylic radical would give a species which could transfer oxygen intramolecularly to give the epoxy acid. Whereas, if the percarboxylic acid involved intermolecular transfer of oxygen would be expected to afford the epoxy acid.

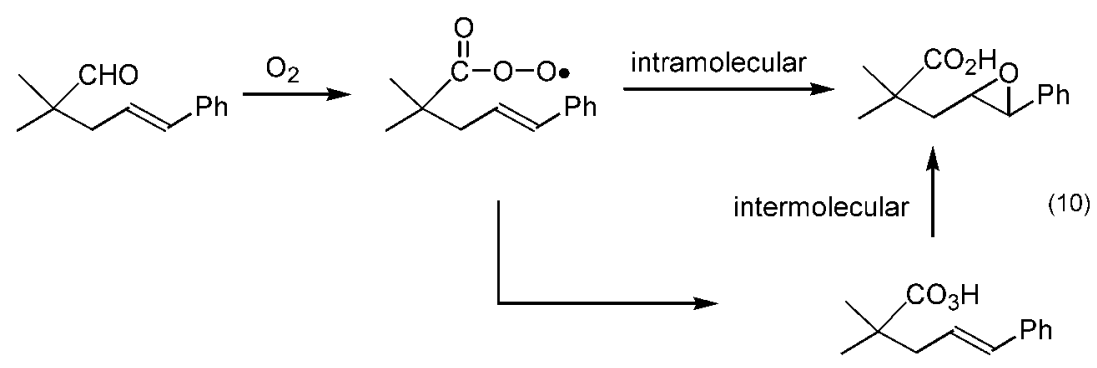

In the experiment, exposure of the aldehyde to oxygen provided the tetrahydrofuranyl product (11). An evaluation of the molecularity of the reaction was carried out using an ester olefin as the intermolecular reporter. The results showed the reporter to be stable in the presence of conversion of the aldehyde olefin to the product, establishing that an intramolecular oxygen transfer occurs in this reaction.

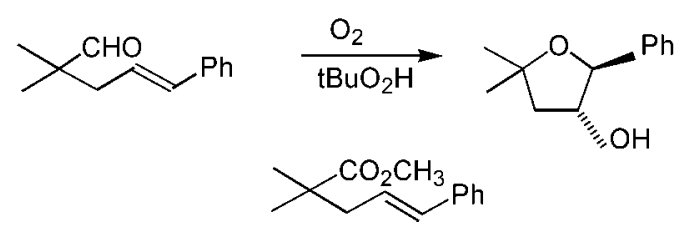


A double-labeling experiment with ${ }^{16} \mathrm{O}_{2}$ and ${ }^{18} \mathrm{O}_{2}$ gave a product consistent with the incorporation of two molecules of oxygen into the sequence. On the basis of these and related experiments, a reaction pathway could be suggested (12).

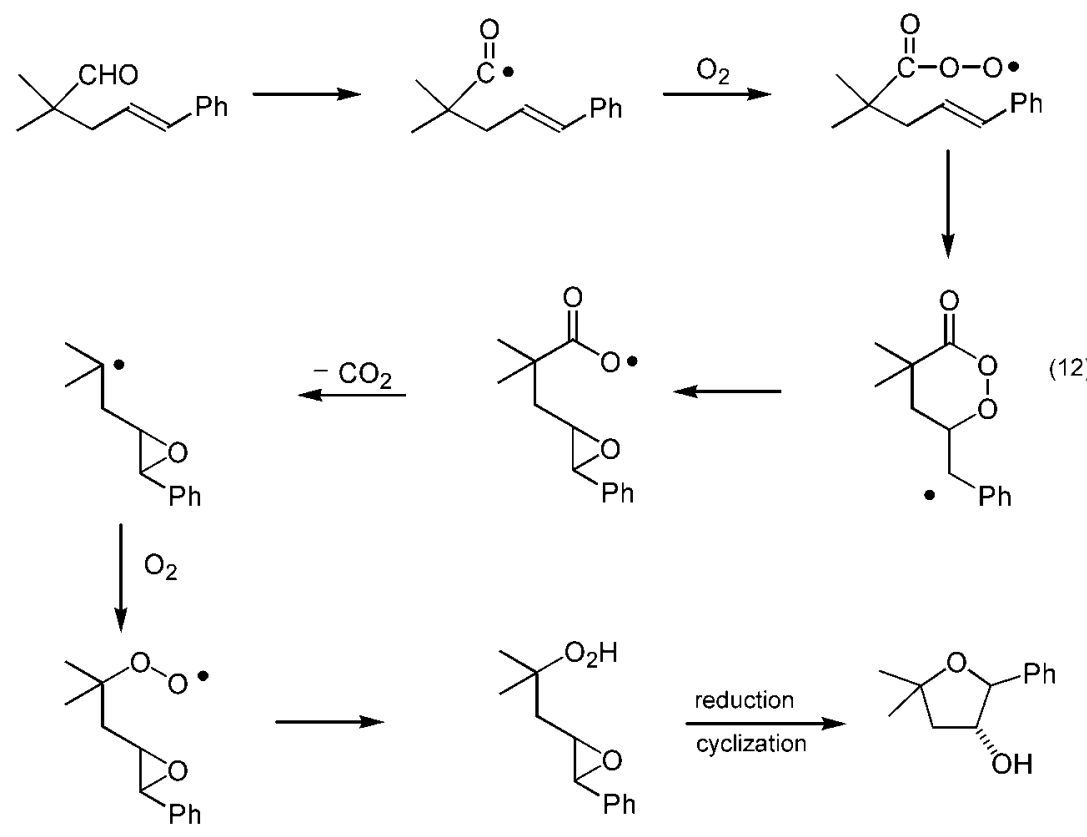

\section{SUMMARY}

Oxygen transfer from an oxygen-nitrogen bond to a second-row atom can involve a small angle in a valance expanded intermediate. The transition-state structures for oxygen transfer from oxygen-oxygen bonds or oxygen-nitrogen bonds to first-row atoms are consistent with the trigonal bipyramid expected from VSEPR or frontier orbital theory. The use of the endocyclic restriction test to determine the transition structures of reactions at oxygen is illustrative of the value of this approach for the evaluation of alternative reaction mechanisms and for extending the description and understanding of reaction profiles.

\section{ACKNOWLEDGMENTS}

We are grateful to the National Science Foundation Grant 99-19422 and the National Institutes of Health GM-18874 for support of this work.

\section{REFERENCES}

1. P. Beak. Pure Appl. Chem. 65, 611 (1993); P. Beak. Acc. Chem. Res. 25, 215 (1992); V. I. Minkin, L. D. Olekhnovich, Y. A. Zhdanov. Molecular Design of Tautomeric Compounds, D. Reidel Publishing, Dordrecht, Holland (1988).

2. L. Tenud, S. Farouq, J. Seible, A. Eschenmoser. Helv. Chim. Acta 53, 2054 (1970).

3. D. R. Hogg and P. W. Vipond. J. Chem. Soc. 2142 (1970).

4. M. L. Kurtzweil, D. Leo, P. Beak. J. Am. Chem. Soc. 45, 421 (1993).

5. K. W. Woods and P. Beak. J. Am. Chem. Soc. 113, 6281 (1991).

6. P. D. Bartlett. Rec. Chem. Prog. 11, 47 (1950). 
7. F. A. Davis and B. C. Chen. Chem. Rev. 27, 919 (1992).

8. D. R. Anderson, K. W. Woods, P. Beak. Org. Lett. 1, 1415 (1999).

9. S. G. Jarboe and P. Beak. Org. Lett. 2, 357 (2000). 